\title{
Çocuklarda sevofluran ile nitröz oksit veya kaudal blok uygulamasının gözlemsel karşılaştırılması
}

\section{Observational comparison of sevoflurane and nitrous oxide or caudal block in pediatric patients}

Nesrin ALPASLAN" Demet COŞKUN²* Sıdıka Hülya ÇELEBi²

'Bayındır Tıp Merkezi, Anesteziyoloji ve Reanimasyon Kliniği, İstanbul/TÜRKIYE

${ }^{2}$ Gazi Üniversitesi Tıp Fakültesi, Anesteziyoloji ve Reanimasyon ABD, Ankara/TÜRKIYE

\section{Öz}

Amaç:Sevofluran çocuklarda anestezi indüksiyonu ve idamesinde en sıktercih edilen volatil anestezikajandır.Çalısmamızda genel anestezinin analjezik komponentini N2O veya kaudal blok ile sağlayarak ve anestezi süresince bisepektral indeks (BIS) monitörizasyonu ile anestezi derinliğini sabit tutarak; bu iki uygulama şeklinin minimal alveolar konsantrasyon (MAK) ve hemodinami üzerindeki etkilerini gözlemsel olarak karşılaştırmayı amaçladık.

Gereç ve Yöntemler: Genel anestezi altında günübirlik operasyon geçirecek 40 çocuk hastaya; \% 40 O2/hava (grup K) veya $\% 40$ O2/N2O (grup N) karışımı içinde \%8 sevofluran kullanılarak inhalasyon indüksiyonu uygulandı. Gurup K'daki çocuklara yan yatar pozisyonda, $22 \mathrm{G}$ kaudal iğneyle $0.7 \mathrm{~mL} / \mathrm{kg}$, \% 0.2 bupivakain solüsyonu kullanılarak kaudal blok uygulandı. Operasyon süresince her iki grubun hemodinamik parametreleri, BIS ve MAK değerleri takip edilerek kaydedildi.

Bulgular: Her iki grubun hemodinamik parametreleri benzer bulunmuştur. Sevofluranın, N2O katkısı olmaksızın kaudal blok yapılan grupta istatiksel yönden anlamlı olmamakla birlikte daha düşük MAK değerlerinde sürdürülebildiği tespit edilmiştir.

Sonuç: Intraoperatif ve postoperatif analjezi sağlamanın yanı sıra çevre kirliliğini azaltması yönünden de bir avantaj sağladığı için kaudal bloğun, anestezi sırasında uygun koşullarda N2O'e göre daha öncelikle tercih edilmesi gerektiği düşüncesindeyiz.

Anahtar Sözcükler: sevofluran anestezisi; nitröz oksit; kaudal blok

Sorumlu Yazar*: Demet Coşkun, Gazi Üniversitesi Tıp Fakültesi, Anesteziyoloji ve Reanimasyon ABD, Ankara/TÜRKiYE 


\begin{abstract}
Aim: Sevoflurane is the most preferred volatile anesthetic agent for the induction and maintenance of anesthesia in children. In our study, the analgesic component of general anesthesia was provided by N2O or caudal block and during anesthesia, the depth of the anesthesia was kept constant by means of the monitoring of bispectral index (BIS). We aimed to make an observational comparison the effects of these two methods on minimal alveolar concentration (MAC) and hemodynamics.
\end{abstract}

Material and Methods: Forty pediatric patients scheduled to undergo on day case based surgery under general anesthesia were included in the study. Inhalation induction using $8 \%$ sevoflurane in a mixture of $40 \%$ O2/Air (group K) or 40\% O2/N2O (group N) were used in all children. Then, patients in Group K received caudal block in lateral decubitus position with $0.7 \mathrm{~mL} / \mathrm{kg}, 0.2 \%$ bupivacaine solution using $22 \mathrm{G}$ caudal needle. Hemodynamic parameters, BIS and MAC values were recorded during the operation in all patients.

Results: Hemodynamic parameters were similar in both groups. It was determined that sevoflurane was not statistically significant in the caudal block group without the contribution of $\mathrm{N2O}$, but could be maintained in lower MAC values.

Conclusion: We recommend use of caudal block since it ensures adequately satisfactory intraoperative and postoperative analgesia without any harm to atmosphere in comparison to $\mathrm{N} 2 \mathrm{O}$ during general anesthesia in the presence of no medical contraindications.

Keywords: sevoflurane anesthesia; nitrous oxide; caudal block

\section{Giriş}

Sevofluran çocuklarda anestezi indüksiyonunda oldukça sık tercih edilen bir volatil anestezik olup, nitröz oksit (N2O) ile birlikte uygulandığında anestezi düzeyine daha hızla ulaşılabilmektedir. Ancak N2O'nun metabolik hastalıklara ve gelişme geriliklerine neden olabilme riski bulunduğu ve ayrıca çevre kirliliği yönünden de sakıncalı olduğu bildirilmiştir [13]. Çocuklarda inguinal herni, sünnet ve inmemiş testis gibi operasyonlarda güçlü intraoperatif ve uzun süren postoperatif analjezik etkisi nedeniyle tercih edilen kaudal blok sıklıkla genel anestezi altında uygulanmaktadır [4]. Anestezi derinliğini ölçmek için geliştirilen bisepektral indeks (BIS) monitörü ile yapılan çalışmalarda, BIS ölçümlerinin çocuklarda da anestezinin hipnotik komponentiyle uyumlu olduğu gösterilmiştir [5].

Buklinikaraştırmada, genelanestezininanaljezikkomponentini N2O veya kaudal blok ile sağlayarak ve anestezi süresince BIS monitorizasyonu ile anestezi derinliğini sabit tutarak; bu iki uygulama şeklinin minimal alveolar konsantrasyon (MAK) ve hemodinami üzerindeki etkilerini gözlemsel olarak karşılaştırmayı amaçladık.

\section{Gereç ve Yöntemler}

Bu klinik araştırma üniversite etik kurul izni (21.02.2005-05) ve ebeveynleringönüllü olur formu alındıktan sonra gerçekleştirildi. Çalışmaya genel anestezi altında ASA I-II risk grubunda 1-12 yaş aralığında; inmemiş testis, inguinal herni, hidrosel gibi günübirlik operasyon geçirecek 40 çocuk dahil edildi.

Çocukların alın bölgesi alkollü pamukla silinip kurulandıktan sonra alınlarına uygun problar yerleştirildi (ASPECTTM,Inc Medical Systems P/N REF 186-0110). BIS Monitörü (A2000, ASPECT Medicak Systems) kullanılarak BIS verileri, XP hiperterminal program yüklenen bilgisayara kaydedildi.

Hastalar kapalı zarf yöntemi kullanılarak, her grupta 20 çocuk olacak şekilde iki gruba ayrıldı. Gruplara \%40 02/ Hava (grup K) veya \%40 02/N2O (grup N) karışımı içinde \%8 sevofluran kullanılarak inhalasyon indüksiyonu uygulandı. Kirpik refleksinin kaybolduğunda sevofluran $\% 5$ 'e düşürüldü. Daha sonra end tidal sevofluran (ETsev) \% 2.2-2.3 aralığında 5 dakika sürdürüldü ve daha sonra uygun laringeal maske (LMA) yerleştirildi. İdame döneminde BiS değerleri 40-60 sınırlarında olacak şekilde ETsev konsantrasyonu ayarlandı.

Grup K'da çocuklar yan pozisyona getirildi, 22 G kaudal iğneyle (Epican ${ }^{\circledast}$ Paed, B Braun Melsungen AG) $0.7 \mathrm{~mL} / \mathrm{kg}$, \% 0.2 bupivakain solüsyonu yavaş enjekte edilerek kaudal blok uygulanıp hasta sırtüstü pozisyona alındı ve cerrahi hazırlığı takiben operasyon başladı. Intraoperatif olarak kalp atım hızı (KAH), noninvasiv arter kan basıncı (NAKB), periferik oksijen satürasyonu (SpO2) ve end tidal CO2 (ETCO2) monitorize edilerek (Draeger, PM 8060) izlendi. Kaudal blok yapılmayan grupta (grup N), postoperatif analjezi sağlamak için operasyon bitiminde paracetamol $10 \mathrm{mg} / \mathrm{kg}$ IV olarak verildi. Kontrol, indüksiyon, LMA yerleşimi öncesi (Imayö), 
LMA yerleşimi sonrası (Imays), ilk insizyon, cerrahi stimülasyon (periton gerilmesi), cerrahinin 5, 10, 15, 20, 25 ile 30. dakikaları, kapanma dönemi (ET 1), anestezi bitişi/ LMA çıkarılması öncesi (Imaçö), LMA çıkarılması sonrası (Imaçs) ve uyanma (spontan göz açma, ağlama ve hareket etme) evrelerinde her iki grupta; $\mathrm{KAH}$, ortalama arter basıncı (OAB), MAK değerleri ve BIS ölçümleri kaydedildi. Çalışma için yerel etik kurul onayı alındı. Hasta onam formları imzalatıldı.

\section{Bulgular}

Çalışmaya dahil edilen 40 hastanın demografik özelliği ve cerrahi süresi açısından gruplar arasında fark bulunmadı. Anestezi süresi yönünden ise grup K'nın grup N'ye göre istatistiksel olarak anlamlı olarak daha uzun olduğu belirlendi ( $p<0.05)$ (Tablo).

\begin{tabular}{l|c|c|c|}
\multicolumn{4}{|c}{ Tablo. Demografik veriler ve anestezi-cerrahi süreler (Ort \pm SS) } \\
& Grup K (n=20) & Grup N (n=20) & P değeri \\
\hline Yaş (yıl) & $3.9 \pm 2.9$ & $5.3 \pm 3.4$ & - \\
\hline Ağırlık (kg) & $16.5 \pm 7.8$ & $20.8 \pm 9.2$ & - \\
\hline Cinsiyet(K/E) & $0 / 20$ & $1 / 19$ & - \\
\hline Anestezi süresi & $65.6 \pm 15.1$ & $54.80 \pm 23.1$ & $<0.05$ \\
\hline Cerrahi süresi & $43.6 \pm 14.1$ & $42.30 \pm 21.6$ & - \\
\hline
\end{tabular}

Her iki grupta anestezi indüksiyonuna \%8 sevofluran ile başlandığından, başlangıçta MAK değerleri her iki grupta aynı düzeyde tespit edilmiştir. Ancak LMA yerleştirilmesi öncesi, sonrası ve bütün anestezi idamesi süresince, BIS değerleri 40-60 değerleri arasında sabit tutulduğunda, Grup K'da MAK değerleri Grup N'e göre daha düşük ve birbirine paralel olarak seyretmiştir (Şekil 1). Hemodinamik parametreler incelendiğinde ise her iki grubun hem $\mathrm{KAH}$ hem de OAB değerleir normal sınırlar içinde birbirine paralel bir seyir göstermiştir ( $p>0.05$ ) (Şekil 2 ve 3).

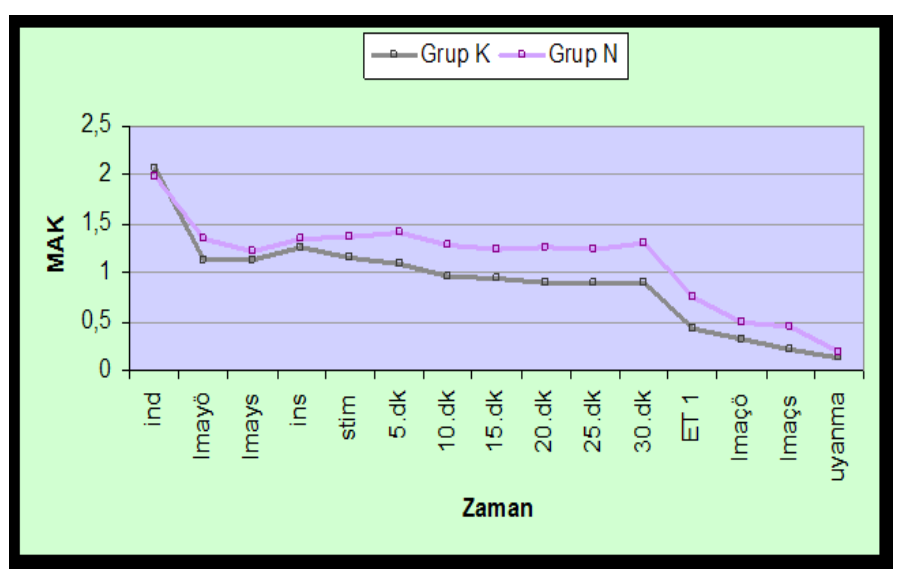

Şekil 1. Grupların minimum alveolar konsantrasyon (MAK) değerleri İnd: indüksiyon, Imayö: LMA yerleşimi öncesi, Imays: LMA yerleşimi sonrası, ins: ilk insizyon, stim: cerrahi stimülasyon, ET 1:kapanma dönemi, Imaçö: LMA çıkarılması öncesi, Imaçs: LMA çıkarılması sonrası

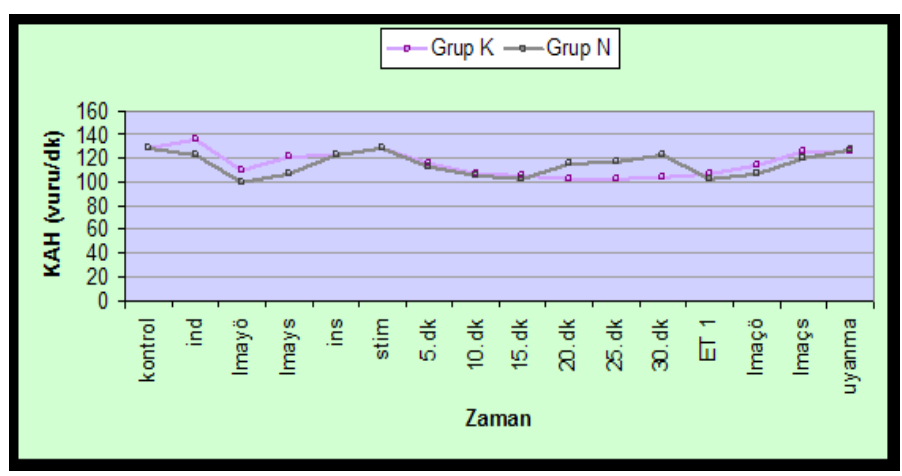

Şekil 2. Grupların kalp atım hızı (KAH) değerleri

İnd: indüksiyon, Imayö: LMA yerleşimi öncesi, Imays: LMA yerleşimi sonrası, ins: ilk insizyon, stim: cerrahi stimülasyon, ET 1:kapanma dönemi, Imaçö: LMA çıkarılması öncesi, Imaçs: LMA çıkarılması sonrası

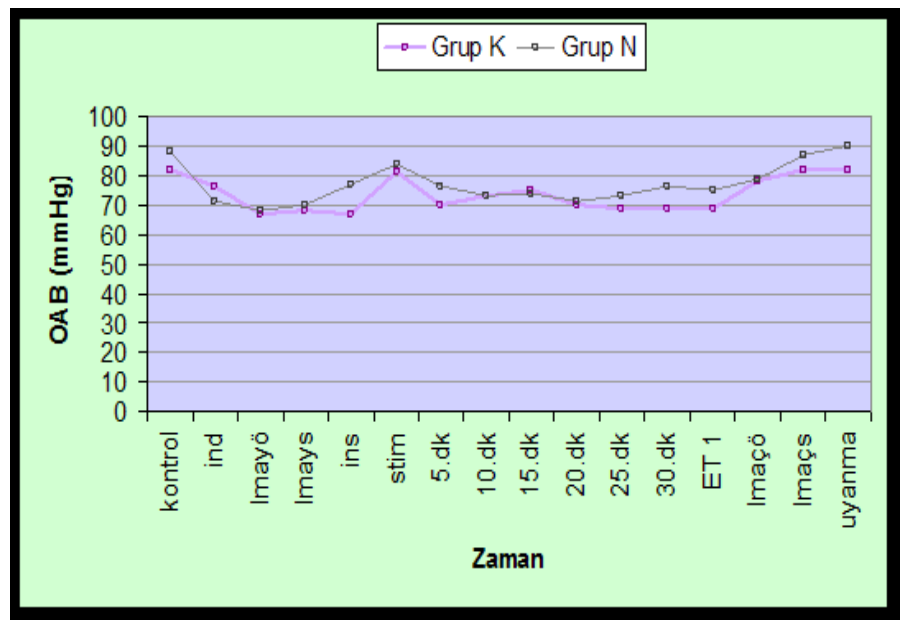

Şekil 3. Grupların ortalama arter basıncı (OAB) değerleri İnd: indüksiyon, Imayö: LMA yerleşimi öncesi, Imays: LMA yerleşimi sonrası, ins: ilk insizyon, stim: cerrahi stimülasyon, ET 1:kapanma dönemi, Imaçö: LMA çıkarılması öncesi, Imaçs: LMA çıkarılması sonrası

\section{İstatistiksel Analiz}

İstatistiksel analizler SPSS (version 20.0 for windows) programında yapıldı. Tüm veriler ortalama \pm standart sapma (Ort \pm SS) veya $\mathrm{n}$ olarak sunuldu. Tamamlayıc istatistikler yapıldıktan sonra tekrarlayan ölçümler (repeated measures) ANOVA ile analiz edildi. Gruplar arası karşılaştırmalar için; parametrik verilerde one-way ANOVA, nonparametrik verilerde ise Ki-kare testi kullanıldı ve $p<0.05$ istatistiksel olarak anlamlı kabul edildi.

\section{Tartışma}

Çalışmamızda; genel anestezinin hipnotik komponenti sevofluran ile analjezik komponenti ise N2O veya kaudal blok ile sağlanarak ve anestezi süresince BIS monitorizasyonu ile anestezi derinliği sabit tutularak, bu uygulamaların MAK ve hemodinamik parametreler üzerindeki etkileri takip edilmiştir. 
Sevofluranın N2O katkısı olmaksızın kaudal blok yapılan grupta, istatiksel yönden anlamlı olmamakla birlikte diğer gruba göre daha düşük MAK değerlerinde sürdürülebildiği, bununla birlikte hemodinamik açıdan incelendiğinde her iki gruptaki sonuçların birbirine benzer olduğu tespit edilmiştir. Çocuklarda ağrıya maruz kalmanın davranış değişikliklerine yol açtığı gösterilmiştir. Bu sebeple cerrahi işlemlerde ağrının etkin bir şekilde giderilmesi önem arz etmektedir [6,7]. Kaudal blok çocuk hastalarda göbek altındaki cerrahi işlemlerde güvenli ve etkili bir analjezi yöntemidir [4]. Bunun yanında postoperatif dönemde güçlü analjezik etki sağlaması, hastanın hızla mobilize olması, dolaşımda stres hormon düzeyinin normal sınırlarda kalması ve ek analjezi gereksinimin azalması gibi birçok fayda sağlamaktadır. Genel anestezi ile birlikte yapılan kaudal bloğun intraoperatif inhalasyon ajan tüketimini ve opiod gereksinimini azalttığı saptanmıştır $[8,9]$. Bu nedenlerle günümüzde çocuklarda genel anesteziyle birlikte yapılan bölgesel veya santral blok uygulamalarına ilgi gittikçe artmaktadır [10]. Özellikle fıtık, sünnet, inmemiş testis gibi operasyonlarda güçlü ve uzun süreli analjezi etkisi nedeniyle tercih edilen kaudal blok sıklıkla genel anestezi altında uygulanmaktadır [4].

Nitröz oksit ikincil gaz etkisi ile volatil anestiziklerin konsantrasyonlarını hızla yükseltmesinin yanı sıra intraoperatif analjezik etkisi nedeniyle de genel anestezide kullanılmaktadır [2]. Keskin kokulu olmaması, hızlı ve yumuşak inhalasyon indüksiyonu sağlaması nedeniyle çocuk hastalarda sıkça kullanılan bir volatil anestezik olan sevofluran, N2O ile birlikte uygulandığında, LMA yerleştirilmesine oluşan yanıtın daha iyi baskılandığı görülmüştür [11]. Bunun yanı sıra N2O; maruziyet süresinin artması oranında postoperatif bulantı ve kusma olasılığının artması, özellikle intraabdominal operasyonlar sırasında batın içi basıncın yükselme riskinin oluşması ve vitamin B12 bağımlı metiyonin sentaz ile timidilat sentaz enzimlerinin inhibisyonu gibi istenmeyen etkilere de yol açabilmektedir [12,13]. Ayrıca N2O kullanılan hastalarda DNA hasarının arttığı ve daha çok postoperatif yara yeri enfeksiyonları ile karşılaşıldığı tespit edilmiştir [14]. Opere olan hastaların yanı sıra özellikle ameliyathanede çalışanlar için de N2O maruziyeti önemli bir sorun teşkil etmektedir [1,3].

Anestezi sırasında kortikal aktivite seviyeleri, hem anestezik maddenin kortikal konsantrasyonu hem de subkortikal uyaran veya uyarılma derecesi ile belirlenir. Rejyonel anestezi subkortikal uyarılma derecesini etkiler. Çocuklarda kaudal bloğun BIS ile ölçülen uyarılma düzeyini azalttığı bulunmuştur
[5]. Bununla birlikte epidural bloğun sevofluranın MAK değerini, dolayısıyla hedeflenen BIS değerine $(<50)$ ulaşmak için gerekli olan sevofluran dozunu azalttığı da gösterilmiştir $(15,16)$. Biz de çalışmamızda BIS monitörizasyonu kullanarak anestezi derinliğini sabit bir düzeyde tutarken, sevofluran ile birlikte yapılan iki değişik uygulama şeklinin MAK ve hemodinami üzerindeki etkilerini tespit etmek istedik.

Kaudal blok ile intraoperatif ve postoperatif etkin analjezi sağlanabilmesi için seçilen lokal anestezi ile kullanılan volüm ve konsantrasyonun önemli olduğu bilinmektedir. Çocuklarda artmış kardiyak output; lokal anesteziklerin dokulardan vaskuler emiliminin artmasına, hızla yüksek başlangıç plazma konsantrasyonlarına ulaşmasına dolayısıyla etki süresinin azalmasına ve sistemik toksisite yaratma ihtimalinin artmasına sebep olmaktadır [17]. Bu nedenle daha yüksek bazal kalp hızı nedeniyle kardiyak toksisite riski artmış olan özellikle 2 yaşından küçük çocuklarda lokal anestezik dozları azaltılmalıdır. Çocuklarda yapılan rejyonel anestezi çalışmalarında kaudal blokta kullanılan lokal anestezikler ve dozları oldukça değiş̧kendir. Kaudal blok uygulamasında; 2 mg/kg'ı geçmemek koşuluyla \%0,2 ropivakain, 2,5 mg/kg'ı geçmemek koşuluyla $\% 0,25$ levobupivakain / bupivakain önerilen dozlardır [18]. Rejyonel anestezi sonrası motor bloğun uzun sürmesi hem ailelerde endişe yaratmakta, hem de geç taburculuk nedeniyle operasyon sonrası bakım ünitelerinin daha fazla meşgul olmasına neden olmaktadır. Bu nedenle lokal anestezik ajanının konsatrasyon ve volümünün özenle seçilmesi önemlidir. Biz de çalışmamızda; kaudal blok için lokal anestezik olarak güçlü ve uzun süreli analjezik etkisi nedeniyle bupivakaini tercih ettik. Kliniğimizde ilk uygulamalarda bupivakain \% 0.25 konsatrasyonda ve $0,5 \mathrm{~mL} / \mathrm{kg}$ volümünde kullanılırken, zaman içinde daha düşük konsantrasyon $(\% 0,2)$ ve daha yüksek volüm $(0,7 \mathrm{~mL} / \mathrm{kg})$ tercih edilerek uzun süreli blok riski giderilmiştir. Bu şekilde yapılan uygulamayla analjezik yarar korunarak, motor blok önlenebilmekte veya şiddeti azaltılabilmektedir. Volümü arttırmanın diğer bir yararı da, daha yüksek seviyelerde blok oluşması ve dolayısıyla bloğun geriye dönüş süresinin uzaması, böylece postoperatif analjezinin daha uzun süre devam etmesinin sağlanmış olmasıdır.

Çalışmamızdaherikigruphemodinamikaçıdan incelendiğinde; $\mathrm{KAH}$ ve $\mathrm{OAB}$ yönünden birbirine benzer sonuçlar bulunmuştur. Bununla birlikte sevofluranın, N2O katkısı olmaksızın kaudal blok yapılan grupta, hedeflediğimiz BIS değerinde, istatiksel yönden anlamlı olmamakla birlikte diğer gruba göre daha düşük MAK değerlerinde sürdürülebildiği, bundan dolayı 
sevofluran tüketiminin de diğer gruba göre daha az olduğu tespit edilmiştir. Kaudal blok uygulamasının belli bir zaman alması nedeniyle, bu grupta anestezi süresi diğer gruba göre istatistiksel olarak belirgin bir şekilde daha uzun bulunmuştur. Ancak yaklaşık olarak 10 dakika olan bu farkın, uygulamanın sağladığı postoperatif analjezi avantajı düşünüldüğünde, çok da önemli olmadığı görüşündeyiz.

\section{Sonuç}

Intraoperatif ve postoperatif analjezi sağlamanın yanı sıra çevre kirliliğini azaltması yönünden de bir avantaj sağladığı için kaudal bloğun, anestezi sırasında uygun koşullarda N2O'e göre daha öncelikle tercih edilmesi gerektiği düşüncesindeyiz.

\section{Çıkar çatışması / finansal destek beyanı}

Bu yazıdaki hiçbir yazarın herhangi bir çıkar çatışması yoktur. Yazının herhangi bir finansal desteği yoktur

\section{Kaynaklar}

1. Lew V, McKay E, Maze M. Past, present, and future of nitrous oxide. Br Med Bull 2018; 125: 103-19.

2. Peyton PJ, Chao I, Weinberg L, Robinson GJ, Thompson BR. Nitrous oxide diffusion and the second gas effect on emergence from anesthesia. Anesthesiology 2011; 114: 596-602.

3. Baum VC. When nitrous oxide is no laughing matter: nitrous oxide and pediatric anesthesia. Paediatr Anaesth 2007; 17: 824-30.

4. Silvani P, Camporesi A, Agostino MR, Salvo I. Caudal anesthesia in pediatrics: an update. Minerva Anestesiol 2006; 72: 453-9.

5. Davidson AJ, Ironfield CM, Skinner AV, Frawley GP. The effects of caudal local anesthesia blockade on the bispectral index during general anesthesia in children. Paediatr Anaesth 2006; 16: 828-33.

6. Kain ZN, Mayes LC, Caldwell-Andrews AA, Karas DE, McClain BC. Preoperative anxiety, postoperative pain, and behavioral recovery in young children undergoing surgery. Pediatrics 2006; 118: 651-8.

7. Taddio A, Katz J, Ilersich AL, Koren G. Effect of neonatal circumcision on pain response during subsequent routine vaccination. Lancet 1997; 349: 599-603.

8. Tobias JD. Postoperative analgesia and intraoperative inhalational anesthetic requirements during umbilical herniorrhaphy in children: postincisional local infiltration versus preincisional caudal epidural block. J Clin Anesth 1996; 8: 634-8.
9. Kim SH, Chun DH, Chang CH, Kim TW, Kim YM, Shin YS. Effect of caudal block on sevoflurane requirement for lower limb surgery in children with cerebral palsy. Paediatr Anaesth 2011; 21: 394-8.

10. Ivani G, Mossetti V. Regional anesthesia for postoperative pain control in children: focus on continuous central and perineural infusions. Paediatr Drugs 2008; 10: 107-14.

11. Kihara S, Yaguchi $Y$, Inomata S, Watanabe S, Brimacombe JR, Taguchi N, Komatsuzaki T. Influence of nitrous oxide on minimum alveolar concentration of sevoflurane for laryngeal mask insertion in children. Anesthesiology 2003; 99: 1055-8.

12. Myles PS, Chan MT, Kasza J, Paech MJ, Leslie K, Peyton PJ, Sneyd $J R$. Severe nausea and vomiting in the evaluation of nitrous oxide in the gas mixture for anesthesia II trial. Anesthesiology 2016; 124: 1032-40.

13. Pichardo D, Luginbuehl IA, Shakur Y, Wales PW, El-Sohemy A, O'connor DL. Effect of nitrous oxide exposure during surgery on the homocysteine concentrations of children. Anesthesiology 2012; 117: 15-21.

14. Chen Y, Liu X, Cheng CH, Gin T, Leslie K, Myles P, Chan MT. Leukocyte DNA damage and wound infection after nitrous oxide administration: a randomized controlled trial. Anesthesiology 2013; 118: 1322-31.

15. Hodgson PS, Liu SS, Gras TW. Does epidural anesthesia have general anesthetic effects? A prospective, randomized, doubleblind, placebo-controlled trial. Anesthesiology 1999; 91: 1687-92.

16. Hodgson PS, Liu SS. Epidural lidocaine decreases sevoflurane requirement for adequate depth of anesthesia as measured by the Bispectral Index monitor. Anesthesiology 2001; 94: 799-803.

17. Desgranges FP, Desebbe O, Pereira de Souza Neto E, Raphael D, Chassard D. Respiratory variation in aortic blood flow peak velocity to predict fluid responsiveness in mechanically ventilated children: a systematic review and meta-analysis. Paediatr Anaesth 2016; 26: 37-47.

18. Suresh S, Ecoffey C, Bosenberg A, Lonnqvist PA, de Oliveira GS Jr, de Leon Casasola O, Ivani G. The European Society of Regional Anaesthesia and Pain Therapy/American Society of Regional Anesthesia and Pain Medicine Recommendations on Local Anesthetics and Adjuvants Dosage in Pediatric Regional Anesthesia. Reg Anesth Pain Med 2018; 43: 211-6. 